\title{
THE PRACTICE OF ACUPUNCTURE IN SAUDI ARABIA
}

\author{
Al-Rukban MO \\ Department of Family and Community Medicine, College of Medicine, King Saud University, Saudi Arabia.
}

\begin{abstract}
:
Acupuncture is one of the oldest and most commonly used complementary medical procedures in the World. Although it is not free from side effects, its use is becoming increasingly popular. The aims of this study were to describe the demographic characteristics of acupuncture users in Riyadh, Saudi Arabia and their knowledge, attitude and experience regarding acupuncture, as well as to determine the common complaints for which patients seek help from acupuncture centers. A cross sectional study, which targeted patients who attended acupuncture centers in Riyadh city during the study's period. Most of the study participants were 21-40 years of age and about two third of them were males. The most common complaints that lead to acupuncture visits were joint pain (22.4\%) and headache (18.6\%). Dissatisfaction with medical treatment and side effects of medications were the major reasons, which led patients to seek cure from acupuncture therapy. About $65 \%$ of the patients heard of acupuncture from their families and friends. Pain sensation from needle puncture was the most noticed side effect (15.8\%). Twenty-two patients completed treatment during the study period and out of those, twenty one patients claimed that they were successfully treated. The practice of acupuncture in Saudi Arabia is not well established. Pain seems to be the most common symptom that guides patients to attend acupuncture centers. There is need for education related to the appropriate use of acupuncture in Saudi Arabia.
\end{abstract} (JUMMEC 2010; 13(2): 93-101)

KEYWORDS: acupuncture, complementary medicine, Saudi Arabia

\section{Introduction}

Complementary and alternative medicine (CAM) is defined by the National Center for Complementary and Alternative Medicine in the United States of America (US) as a group of diverse medical and health-care systems, practices and products that are not presently considered to be part of conventional medicine (1).

Interest in CAM has grown considerably worldwide. The number of doctors who practice CAM therapies, possess CAM knowledge, and desire to practice such therapies has increased over the last decade (2-10).

The prevalence of the types of CAM practice varies from country to country. For example, the CAM modes of therapy for which $51 \%$ of physicians in the US would most often practice and refer their patients were: acupuncture, vitamin therapy, herbal therapy, lifestyle diet, mineral therapy, and anti-oxidant therapy
(11). In the Netherlands, $51 \%$ of physicians practiced chiropractic therapy (12). In Germany, $78 \%$ of physicians practiced herbal medicine, and $45 \%$ homeopathy (13). Furthermore, complementary medicine treatments are used by $16 \%$ of general practitioners in Britain and Canada, and by $30 \%$ general practitioners in New Zealand (3).

Correspondence:

Mohammed O. Al-Rukban

Department of Family and Community Medicine

College of Medicine,

King Saud University

P.O. Box 91678,

Riyadh 11643, Saudi Arabia

E-mail:mrukban@hotmail.com 
Acupuncture is now considered as the most popular treatment of complementary and alternative medicine $(7,13-18)$. It is one of the oldest medical procedures in the World. It originated in China more than 2,000 years ago and began to gain popularity in the US in 1971 (19).

In acupuncture, the symptoms are improved by a group of procedures involving stimulation of anatomical points on the body by a variety of techniques. Acupuncture technique is charaterized by inserting a thin, solid and metallic needle into selected points beneath the skin that are manipulated by the hand or by electrical stimulation. The needles are stimulated by either rotation or, more recently by electric current. Hypotheses suggest that needling activates deep sensory nerves, which cause the pituitary and midbrain to release endorphins, the brain's natural pain killers $(20,21)$.

Acupuncture is widely used in the Far East for the relief of pain and in China it has become an alternative to anaesthesia for some major operations (20). It is now recognized in the US, where it is used to treat many conditions including headache, back pain, nausea, stress, infertility, fatigue, allergic sinusitis, neuralgia, and smoking cessation (21).

Despite the increasing usage and demand for acupunture in the World, little is known about its use in our community. This study aims to elaborate more on some issues related to acupuncture use in Saudi Arabia, including: (a) the demographic characteristics of acupuncture users, (b) the users' knowledge, attitude, and experience regarding acupuncture as a therapeutic modality, and (c) the common complaints for which patients visit the acupuncture centres in Riyadh.

\section{Methods}

Study population and sampling: This cross sectional study targeted patients who visited complementary centres for acupuncture treatment in Riyadh city. In Riyadh, there are five centres for acupuncture therapy. Most of the procedures at these centres were conducted by Traditional Chinese Medicine (TCM) practitioners. However, few graduates of conventional medicine who follow the TCM approach were also involved. All patients treated at these centres during the study period (from February to April, 2005) were invited to be a part of the study.
Data collection form: Data was collected by using a self-reported questionnaire. The author and the research assistants (eight third year medical students) developed the questionnaire after reviewing related literature (22-26). The questionnaire consisted of 27 items addressing demographic characteristics of acupuncture users, their knowledge and beliefs about acupuncture, the common complaints which brought them to acupuncture centres, common side effects noticed by the patients, and their suggestions about improvement of this service in the country.

Data collection: A list of acupuncture centres in Riyadh was obtained from the Ministry of Health after which questionnaires were distributed to the patients who were being treated at these centres. The aim of the study and the data collection technique were fully explained to the centres' administrators and one responsible staff from each centre was assigned to collect the data. Research assistants trained the data collectors, who distributed the questionnaires to the patients and helped them during the administration of questionnaires without volunteering information for the questionnaire. During the study period, the research assistants visited the centres regularly and the questionnaires were collected three times a week. Telephone contact with the responsible person in the centres was conducted daily.

The questionnaire was administered to each patient once. Whenever a patient visited the centre, he/she was asked to fill the questionnaire. Patients, therefore, participated in the study at different points of their treatment course.

Data analysis: Questionnaires were managed and coded by the investigator and the research assistants. Data entry and analysis were through SPSS program (Version. 11) and chi-square and Fisher's exact test were used to study the association between different variables. P-value was considered statistically significant when $<0.05$.

\section{Results}

A total of 183 patients participated in this study. The majority of the patients (55.1\%) attending the acupuncture centres were 21-40 years of age. About two third of the acupuncture users were males and $65 \%$ of the patients were married. The majority of 
Table 1: Demographic characteristics of patients who attended acupuncture centers in Riyadh, KSA.

\begin{tabular}{|c|c|c|}
\hline Variable & Frequency & Percentage \\
\hline \multicolumn{3}{|l|}{ Age } \\
\hline Less than 11 years & 1 & 0.5 \\
\hline $11-20$ years & 12 & 6.6 \\
\hline $21-40$ years & 101 & 55.1 \\
\hline 41-60 years & 59 & 32.1 \\
\hline Older than 60 years & 10 & 5.5 \\
\hline \multicolumn{3}{|l|}{ Sex } \\
\hline Male & 116 & 63.4 \\
\hline Female & 67 & 36.6 \\
\hline \multicolumn{3}{|l|}{ Marital status: } \\
\hline Single & 63 & 34.4 \\
\hline Married & 120 & 65.6 \\
\hline \multicolumn{3}{|l|}{ Nationality } \\
\hline Saudi & 167 & 91.8 \\
\hline Non Saudi & 15 & 8.2 \\
\hline \multicolumn{3}{|l|}{ Residency } \\
\hline In Riyadh & 153 & 83.6 \\
\hline Outside Riyadh city (village) & 10 & 5.5 \\
\hline Outside Riyadh city (city) & 20 & 10.9 \\
\hline \multicolumn{3}{|l|}{ Job } \\
\hline Government employee & 50 & 27.3 \\
\hline Private employee & 41 & 22.4 \\
\hline Serviceman & 11 & 6 \\
\hline Business & 14 & 7.7 \\
\hline Student & 36 & 19.7 \\
\hline Retired & 7 & 3.8 \\
\hline Housewife & 24 & 13.1 \\
\hline \multicolumn{3}{|l|}{ Educational level } \\
\hline Illiterate & 9 & 4.9 \\
\hline Primary school & 5 & 2.7 \\
\hline Secondary or High school & 70 & 38.3 \\
\hline University & 88 & 48.1 \\
\hline Higher education & 11 & 6.0 \\
\hline Total & 183 & 100 \\
\hline
\end{tabular}

them (91.8\%) were Saudis. Approximately $84 \%$ of the patients who visited the acupuncture centres were from Riyadh city. Slightly more than half of the patients were highly educated, with a minimum of a university degree (Table 1).

About $65 \%$ of the patients heard of acupuncture from their families and friends. Internet (32.8\%), handbills distributed by the acupuncture centres (26.8\%) and the media (21.3\%) were also common sources of information. Only two patients were actually referred by medical professionals.
The most common complaints of patients who came to acupuncture centres were joint pain (22.4\%), headache $(18.6 \%)$, lower back pain $(15.8 \%)$, chronic neck pain (14.8\%) and obesity (13.7\%) (Table 2 ).

Most of the patients had used some complementary treatments before they decided to try acupuncture therapy. These therapies included physical therapy (23.5\%), herbs (20.2\%), Holy Quran recitation (12.6\%), cupping (7.7\%) and cautery (2.2\%).

Several reasons were cited by patients as influencing their decision to use acupuncture therapy. The major 
Table 2: The health complaints that brought patients to acupuncture centers

\begin{tabular}{|c|c|c|}
\hline The Health Problem & Frequency & Percentage \\
\hline Arthralgia & 41 & 22.4 \\
\hline Headache & 34 & 18.6 \\
\hline Lower back pain & 29 & 15.8 \\
\hline Chronic neck pain & 27 & 14.8 \\
\hline Obesity & 25 & 13.7 \\
\hline Chronic shoulder pain & 19 & 10.4 \\
\hline Muscular weakness & 19 & 10.4 \\
\hline Rehabilitation after CVA & 17 & 9.3 \\
\hline Smoking & 15 & 8.2 \\
\hline Asthma & 14 & 7.7 \\
\hline Digestive diseases & 14 & 7.7 \\
\hline Improvement of general health & 13 & 7.1 \\
\hline Psychological and emotional illness & 11 & 6.0 \\
\hline Rehabilitation after CVA & 17 & 9.3 \\
\hline Chest diseases & 9 & 4.9 \\
\hline Dysmenorrhoea & 7 & 3.8 \\
\hline Hypersensitivity of the skin & 5 & 2.7 \\
\hline Amenorrhea & 4 & 2.2 \\
\hline Female pelvic inflammation & 2 & 1.1 \\
\hline Accidents complications & 2 & 1.1 \\
\hline
\end{tabular}

Table 3: Patients' perceptions of the side effects caused by acupuncture

\begin{tabular}{lcc}
\hline Side effect & Frequency & Percentage \\
\hline Painful sensations of needle puncture & 29 & 15.8 \\
Infectious diseases ( AIDS \& Hepatitis ) & 17 & 9.3 \\
Spinal cord injuries & 13 & 7.1 \\
Bruises in area of needles & 12 & 6.6 \\
Skin allergy & 9 & 4.9 \\
Numbness of limbs & 9 & 4.9 \\
Hypersensitivity & 8 & 4.4 \\
Nausea & 8 & 3.3 \\
Vertigo & 6 & 3.3 \\
Fatigue and Tiredness & 6 & 3.3 \\
Nerve destructions & 6 & 2.7 \\
Urticaria & 6 & 2.7 \\
Inflammations & 5 & 2.2 \\
Bleeding disorders & 5 & 2.2 \\
Increases of sweating & 5 & 2.2 \\
Headache & 4 & 1.6 \\
\hline
\end{tabular}


Table 4: The patients' knowledge of the diseases that could be treated with acupuncture.

\begin{tabular}{|c|c|c|}
\hline Side effect & Frequency & Percentage \\
\hline Headache & 116 & 63.4 \\
\hline Joint pain & 106 & 57.9 \\
\hline Chronic neck pain & 105 & 57.4 \\
\hline Lower back pain & 94 & 51.5 \\
\hline Chronic shoulder pain & 87 & 47.5 \\
\hline Muscular weakness & 83 & 45.4 \\
\hline Obesity & 75 & 41.0 \\
\hline Smoking & 69 & 37.7 \\
\hline Asthma & 63 & 34.4 \\
\hline Chest diseases & 56 & 30.6 \\
\hline Digestive diseases & 54 & 29.5 \\
\hline Improving general health & 53 & 29.0 \\
\hline Paralysis & 45 & 24.6 \\
\hline Rehabilitation after CVA & 38 & 20.8 \\
\hline Psychological and emotional illness & 36 & 19.7 \\
\hline Dysmenorrhea & 33 & 18.0 \\
\hline Drugs or Alcohol addiction & 33 & 18.0 \\
\hline Amenorrhea & 32 & 17.5 \\
\hline Hypersensitivity of the skin & 32 & 17.5 \\
\hline Female pelvic inflammation & 31 & 16.9 \\
\hline Impotence & 28 & 15.3 \\
\hline Uterine bleeding & 27 & 14.8 \\
\hline Food allergy & 23 & 12.6 \\
\hline
\end{tabular}

reasons included: dissatisfaction with results of medical treatment (67.2\%), medication side effects (25.7\%), poor conventional health services (19.7\%), long waiting time at the health centres (18.0\%), high cost of medical interventions (16.4\%) and incompetence of health care workers (14.8\%).

Among patients who were asked about the reasons for their confidence in acupuncture, $94.5 \%$ stated that they trusted the effectiveness of acupuncture and $41 \%$ believed that acupuncture has only few side effects.

Very few patients were aware of common side effects resulting from acupuncture therapy (less than $22 \%)$. The most common acupunctural side effects cited by the patients were: pain sensation from needle puncture (15.8\%), infectious diseases like AIDS and hepatitis $(9.3 \%)$, spinal cord injuries $(7.1 \%)$ and bruises in the areas of needle punctures (6.6\%) (Table 3 ).
Regarding their belief about the diseases that can be treated by acupuncture, almost $63 \%$ of patients identified headache and $57.9 \%$ identified joint pain. Patients also believed that acupuncture is useful for the treatment of chronic neck pain (57.4\%), lower back pain $(51.5 \%)$, chronic shoulder pain $(47.5 \%)$, muscular weakness (45.4\%) and obesity (41\%) (Table 4).

Of the 22 patients, who completed the course of acupuncture therapy during the period of this study, 21 patients felt that they were successfully treated, while one had failed to improve. The remaining patients are still under treatment.

More than $84 \%$ of the participants supported the idea of opening of new acupuncture centres in the city and the expansion of its practice. Most of those, who were supported expansion of acupuncture practice, 
Table 5: Patients' opinions toward the expansion of the acupuncture practice in the country

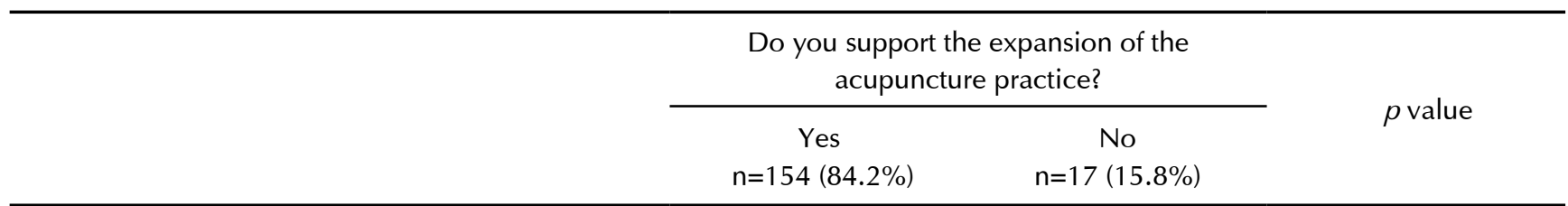

The negative points of the health centers that lead to the use of acupuncture treatment

$\begin{array}{lccc}\text { High cost } & 26 & 3 & 0.58^{* *} \\ \text { Long waiting lists } & 28 & 3 & 0.63^{* *} \\ \text { Low qualification of the health workers } & 23 & 2 & 0.53^{* *} \\ \text { Bad health services } & 31 & 4 & 0.47^{* *} \\ \text { Drug side effects } & 35 & 4 & 0.57^{* *} \\ \text { Dissatisfactory results of the treatment } & 114 & 5 & 0.0004^{*}\end{array}$

Patients trust of the results of acupuncture

$\begin{array}{lrrr}\text { Trusting } & 151 & 10 & 0.00001 \\ \text { Not trusting } & 3 & 7 & \end{array}$

Do you know the side effects of the acupuncture?

$\begin{array}{lrrr}\text { Yes } & 31 & 5 & 0.27^{* *} \\ \text { No } & 123 & 12 & \end{array}$

The results of the acupuncture treatment

$\begin{array}{lrrr}\text { The treatment was successful } & 21 & 0 & 17 \\ \text { I am still being treated } & 132 & 0 & 0.248 \\ \text { The treatment failed } & 1 & \end{array}$

* chi-square test,${ }^{* *}$ Fisher's exact test

were dissatisfied with the results of treatment in health centres $(p<0.05)$, where as those who did not have trust in the effectiveness of acupuncture practice were against its expansion, $p<0.05$, (Table 5 ).

\section{Discussion}

As far as we know, this study is the first study in Saudi Arabia that has tried to elaborate in detail the patients' perceptions and beliefs regarding the practice of acupuncture in the kingdom.

Only 183 patients were seen in five centres in Riyadh over a two months period. This is surprisingly a very low number and requires adequate explanation. It could indicate that the practice of acupuncture in Saudi Arabia is still not well respected or accepted by the community. Another possible reason for the low number could be that, not all patients who attended the centres actually completed the questionnaire. If this is true, then it could be a very important limitation of the study. Furthermore, the fact that all acupuncture centres in Riyadh are private clinics could discourage patients to seek acupuncture treatment due to the extra cost involved.

The study revealed a fair understanding of the patients' perception of the positive role of acupuncture in the management of some common complaints. However, the patients' level of perceptions of acupuncture's side effects was below expectations.

Acupuncture is increasingly popular among patients in most country, but it is not free of risks. The 
adverse events documented for acupuncture have been very minimal (27-30). Ernst et al (28) found that the most common adverse events were needle pain $(1 \%-45 \%)$, bleeding $(0.03 \%-38 \%)$, and faintness or syncope $(0 \%-0.3 \%)$. The potential risks are generally thought to include bruising, bleeding, haematoma, pain, infection, possible fainting, aggravation of neuropathy, and feeling of electrical shock. In our study the most common side effect cited by the patients was needle pain (15.8\%).

This study revealed that many patients who were treated with acupuncture were middle aged and highly educated. This tendency was same as that reported in many previous surveys (31-34) and could probably be due to the trend of trying new treatment modalities.

The study also revealed that males visited acupuncture centres more frequently than females. This finding is inconsistent with the international trends in the use of alternative medicine $(3,35,36)$. In Australia, for example, most of the patients who regularly visited acupuncture centres were women (3). This may be due to the tendency of Saudi males to move more freely between different health care institutions for seeking cure of their problems. Women may also be less aware of this form of treatment. The most common reason for utilization of acupuncture in the present survey was recommendation of family or friends'. The second most important reason reflects dissatisfaction or distrust with conventional medical therapies. This is compatible with the findings of another study, which found that, in general, patients who seek the help of acupuncturists were less satisfied with conventional medicine and on the other hand trusted acupuncture (36).

In this study, pain seems to be the most common symptom that drives patients to seek help from the acupuncture centres. Similar results were found in Germany $(34,37)$ and in Japan $(36)$. Conventional medical treatment may fail sometimes to relieve patient's painful symptoms; on the other hand it may also reflect the strong effect of acupuncture in management of pain disorders $(38,39)$. An important recommendation that could be concluded from this study is that doctors must take patients' need of relief of pain more seriously.
The study indicates that the patients who attended acupuncture centres had overwhelmingly positive perception of the efficacy of acupuncture treatment; this is implicit from the $84.2 \%$ of the patients who support the expansion of its practice.

As most of our studied patients had a positive impression of acupuncture treatment and it also seems to be a growing modality of treatment worldwide, there is need for community education about the appropriate use of acupuncture. Considering use of evidence based complementary medicine, such as acupuncture, in patients' management and its inclusion in medical curriculum may increase patients' satisfaction and trust in our health services.

In conclusion, this study indicates that acupuncture treatment is not popular in the largest city of Saudi Arabia. Pain is the most common complaint which guides patients to seek relief from acupuncture centres. The painful sensation of the needle puncture however, is the main side effect of acupuncture, according to the patients' perceptions. There is need for a similar study at acupuncture centres of several cities and regions of Saudi Arabia before the finding can be generalized for the entire population.

\section{Acknowledgement}

The author would like to thank the research assistants (namely, Mohammad Al-Baik, Hussein Al-Abdulaal, Ali Khulaif, Mahdi Al-Bander, Mansour Al-Ramadhan, Ahmad Al-Harbi, Saeed Al-Meneaei and Ali Abalkhail) for their assistance and collaboration in conducting this study. The author would also like to thank the data collectors for their cooperation. Much thanks to Mr. Ameer who helped in the data entry and analysis and to Dr. Eeman At-Taras, Prof. Riaz Qureshi and Prof. Omar Kasule for revising the final draft of this manuscript.

\section{References}

1. Eisenberg DM, Davis RB, Ettner SL, Appel S, et al. Trends in alternative medicine use in the United States, 1990-1997: Results of a follow-up national survey. JAMA 1998; 280: 1569-1575.

2. Fujiwara K, Imanishi J, Watanabe S, Ozasa K, Sakurada K. Changes in Attitudes of Japanese 
Doctors toward Complementary and Alternative Medicine-Comparison of Surveys in 1999 and 2005 in Kyoto. Evid Based Complement Alternat Med. 2009.

3. Easthope G, Beilby J, Gill G and Tranter B. Acupuncture in Australian general practice: practitioner characteristics. MJA 1998; 169: 197200.

4. Thomas KJ, Nicholl JP, Fall M. Access to complementary medicine via general practice. $\mathrm{Br} J$ Gen Pract. 2001; 51: 25-30.

5. Schachter L, Weingarten MA, Kahan EE. Attitudes of family physicians to nonconventional therapies. A challenge to science as the basis of therapeutics. Arch Fam Med. 1993; 2: 1268-1270.

6. Borkan J, Neher JO, Anson O, Smoker B. Referrals for alternative therapies. J Fam Pract. 1994; 39: 545550.

7. Verhoef MJ, Sutherland LR. Alternative medicine and general practitioners. Opinions and behaviour. Can Fam Physician. 1995; 41: 1005-1011.

8. White $A R$, Resch KL, Ernst E. Complementary medicine: use and attitudes among GPs. Fam Pract. 1997; 14: 302-306.

9. Wearn AM, Greenfield SM. Access to complementary medicine in general practice: survey in one UK health authority. J R Soc Med . 1998; 91: 465-470.

10. Lewith GT, Hyland M, Gray SF. Attitudes to and use of complementary medicine among physicians in the United Kingdom. Complement Ther Med. 2001; 9: 167-172.

11. Kurtz ME, Nolan RB, Rittiger WJ. Primary care physicians' attitudes and practices regarding complementary and alternative medicine. JAOA 2003; 103: 597-602.

12. Visser J. Alternative medicine in the Netherlands. Comp Med Res 1990; 4: 28-31.

13. Himmel W, Schulte M, Kochen MM. Complementary medicine: are patients' expectations being met by their general practitioners? Br J Gen Pract 1993; 43: 893-898.
14. Poynton L, Dowell A, Dew K, Egan T. Family physicians' attitudes toward (and use of) complementary and alternative medicine: a New Zealand nationwide survey. N Z Med J 2006; 119: U2361.

15. Hall K, Giles-Corti B. Complementary therapies and the family physician. A survey of Perth FPs. Aust Fam Physician 2000; 29: 602-606.

16. Xue CC, Zhang AL, Yang AW, Zhang CS, Story DF. Recent developments of acupuncture in Australia and the way forward. Chinese Medicine 2009, 4:7.

17. Xue CC, Zhang AL, Lin V, Da Costa C, Story DF. Complementary and alternative medicine use in Australia: a national population-based survey. J Altern Complement Med 2007; 13(6): 643-650.

18. Cohen MM, Penman S, Pirotta M, Da Costa C. The integration of complementary therapies in Australian general practice: results of a national survey. J Altern Complement Med 2005, 11(6): 9951004.

19. White A, Hayhoe S, Hart A, Ernst E. Adverse events following acupuncture: prospective survey of 32000 consultations with doctors and physiotherapists. BMJ 2001; 323: 485-486.

20. Marith A. Concise Colour Medical Dictionary, 2nd edit. Oxford University Press, 1998.

21. Ma L. Acupuncture as a complementary therapy in chemotherapy-induced nausea and vomiting. Proc (Bayl Univ Med Cent). 2009; 22(2): 138-141.

22. Ernst E, White AR. Acupuncture may be associated with serious adverse events. BMJ 2000; 320: 513514.

23. MacPherson $\mathrm{H}$, Scullion A, Thomas KJ, Walters $\mathrm{S}$. Patient reports of adverse events associated with acupuncture treatment: a prospective national survey. BMJ 2004; 13: 349-355.

24. MacPherson $\mathrm{H}$, Thomas $\mathrm{K}$, Walters S, Fitter M. The York acupuncture safety study: prospective survey of 34000 treatments by traditional acupuncturists. BMJ 2001; 323: 486-487.

25. White A, Hayhoe $S$, Hart A, Ernst E. Survey of adverse events following acupuncture (SAFA): a prospective 
study of 32,000 consultations. Acupunct Med 2001; 19(2): 84-92.

26. Peuker E., Filler T. Guidelines for case reports of adverse events related to acupuncture. Acupunct Med 2004; 1: 29-33.

27. Ezzo J, Vickers A, Richardson MA, Allen C, Dibble SL, Issell B, Lao L, Pearl M, Ramirez G, Roscoe JA, Shen J, Shivnan J, Streitberger K, Treish I, Zhang G. Acupuncture-point stimulation for chemotherapyinduced nausea and vomiting. J Clin Oncol. 2005; 23(28): 7188-7198.

28. Ernst E, White AR. Prospective studies of the safety of acupuncture: a systematic review. Am J Med. $2001 ; 110(6):$ 481-485.

29. Johnstone PA, Polston GR, Niemtzow RC, Martin PJ. Integration of acupuncture into the oncology clinic. Palliat Med. 2002; 16(3): 235-239.

30. Mannix K. Palliation of nausea and vomiting in malignancy. Clin Med. 2006; 6(2): 144-147.

31. Xue CC, Zhang AL, Lin V, Myers R, Polus B, Story DF: Acupuncture, chiropractic and osteopathy use in Australia: a national population survey. BMC Public Health 2008, 8: 105.

32. MacLennan AH, Wilson DH, Taylor AW. Prevalence and cost of alternative medicine in Australia. Lancet 1996; 347: 569-573.

33. Eisenberg DM, Davis RB, Ettner SL, Appel S, Wilkey $\mathrm{S}$, Rompay MV, et al. Trends in alternative medicine use in the United States, 1990-1997. J Am Med Assoc 1998; 280: 1569-1575.
34. Güthlin C, Lange $O$, Walach $H$. Measuring the effects of acupuncture and homoeopathy in general practice: An uncontrolled prospective documentation approach. BMC Public Health. 2004; 4: 6 .

35. Jain N, Astin JA. Barriers to Acceptance: An Exploratory Study of Complementary/Alternative Medicine Disuse. J Altern Complement Med 2001, 7(6): 689-696.

36. Ishizaki N, Yano T, Kawakita K. Public Status and Prevalence of Acupuncture in Japan. Evid Based Complement Alternat Med. 2008.

37. Joos S, Musselmann B, Szecsenyi J. Integration of Complementary and Alternative Medicine into Family Practices in Germany: Results of a National Survey. Evid Based Complement Alternat Med. 2009.

38. Manheimer E, Linde $K$, Lao L, Bouter LM, Berman BM. Meta-analysis: acupuncture for osteoarthritis of the knee. Ann Intern Med 2007; 146: 868-877.

39. Chou R, Huffman LH. American Pain Society; American College of Physicians. Nonpharmacologic therapies for acute and chronic low back pain: a review of the evidence for an American Pain Society/American College of Physicians clinical practice guideline. Ann Intern Med 2007; 147: 492504. 